\title{
UM 'ESTRANHO' ENCONTRO EM BISHKEK: O COMUNISMO-QUEER ENTRE A CRÍTICA MARXISTA E O PÓS- ESTRUTURALISMO BUTLERIANO
}

\section{A 'STRANGER' MEETING IN BISHKEK: QUEER COMMUNISM BETWEEN MARXIST CRITICISM AND BUTLERIAN POST-STRUCTURALISM}

\author{
Pedro Pompeo Pistelli Ferreira ${ }^{1}$
}

\begin{abstract}
Resumo: O presente trabalho é oriundo de exercício de diálogo entre duas diferentes perspectivas: a primeira, mais próxima de nosso horizonte e trajetória de pesquisa, consiste na teoria crítica de base primariamente marxista; e a segunda trata-se de uma crítica de recorte pós-estruturalista, inspirada principalmente na obra de Judith Butler. Busca-se, desse modo, realizar um exercício de deslocamento do pertencimento teórico e um enriquecimento de nosso ponto de partida por meio do diálogo com pensamentos que operam em outros registros. Por se tratar de uma pesquisa ainda de caráter exploratório, adotamos uma metodologia de pesquisa bibliográfica em dois tempos. Primeiramente, abordamos esse debate de uma maneira abstrata no início do artigo, a partir da noção de crítica em Butler e na teoria marxista contemporânea. De modo mais concreto, posteriormente, pretendemos realizar a tarefa de pensar o diálogo acima assinalado a partir de um exercício de deslocamento categorial que consideramos muito instigante: a proposta do comunismo-queer, elaborada no seio da ShTAB, a Escola de Teoria e Ativismo de Bishkek, organização política LGBTQIA+ localizada na capital do Quirguistão e cuja prática teórico-política tenta sintetizar as duas correntes críticas que protagonizam o diálogo que tentamos esboçar.
\end{abstract}

Palavras-chave: Comunismo-queer; Judith Butler; Marxismo; Teoria Crítica; Movimentos LGBTQIA+; Filosofia Política.

Abstract: The present work is a dialogical result between two different streams. The first, closer to our personal scholarly tradition, is the marxist-inspired critical theory. The second one is a post-structuralist critique inspired basically in Judith Butler's work. It seeks, therefore, an effort of dislocation of theoretical belongings and a refinement of our initial view. The way to achieve that consists in the dialogue between thinkings that are used to operate differently. Since we're dealing with exploratory research, our methodological procedures are basically a dual stage work of bibliographic revision. Firstly, we face this discussion in an abstract manner in the beginning of the paper. After that, we seek to show the before mentioned dialogue with a more concrete lighting, exposing a very interesting conceptual dislocation operated by the proposition of a queer-communism, made by ShTAB (School of Theory and Activism of Bishkek), a LGBTQIA+ political organization located in Kyrgyzstan's capital. ShTAB represents a theoretical and political practice that aims to merge creatively both the theoretical streams that are discussed in the present work.

\footnotetext{
1 Doutorando em Direito pela Universidade Federal do Paraná (UFPR) e bolsista de pós-graduação pela CAPES. Mestre em Direitos Humanos e Cidadania pela Universidade de Brasília (UnB). Graduado em Direito pela Universidade Federal do Paraná (UFPR). Associado ao Instituto de Pesquisa, Direitos e Movimentos Sociais (IPDMS). Pesquisador do Núcleo de Direito Cooperativo e Cidadania da UFPR (NDCC-UFPR). E-mail: pedro.pistelli.ferreira@gmail.com.
} 
Keywords: Queer-Communism; Judith Butler; Marxism; Critical Theory; LGBTQIA+ Movements; Political Philosophy.

\section{INTRODUÇÃO}

O presente trabalho é oriundo de exercício de diálogo entre duas diferentes perspectivas: a primeira, mais próxima do nosso horizonte e trajetória de pesquisa passados, consiste na teoria crítica de base primariamente marxista; e a segunda trata-se de uma crítica de recorte pós-estruturalista, inspirada principalmente na obra de Judith Butler, que foi trazida à baila por iniciativa da disciplina Filosofia do Direito, ministrada pela professora Angela Couto Machado da Fonseca, no primeiro semestre de 2020 do PPGD-UFPR, tendo como pano de fundo no plano de ensino as suas possibilidades de conexão com temáticas clássicas e contemporâneas, como as de teoria crítica, descolonialidade, genealogia, política pós-fundacionalista e caminhos para uma crítica ético-política.

Aqui, nossa pretensão não consiste em uma refutação simplista de qualquer uma dessas tendências, que geralmente culmina na criação de espantalhos teóricos e na estereotipação de cada corrente, reduzindo-as a elementos ou a sintomas que os próprios interlocutores não reconheceriam como seus ${ }^{2}$. Pelo contrário, nossa intenção direciona-se a um exercício de deslocamento do pertencimento teórico, que, ao buscar reler a nossa própria tradição de pensamento a partir de outros olhos e perspectivas - o que implica também reconhecer que se tratam de reflexões diversas e não imediatamente homogeneizáveis entre si -, intenta ampliar nosso horizonte e, a partir desse diálogo e de uma abertura à transformação de nossas certezas, fortalecer a possibilidade mesma de reconstrução de nossas inspirações a partir de novas indagações, estruturadas por propostas teóricas que operam a partir de outros registros.

\footnotetext{
2 Esse processo ocorre, por exemplo, quando autores marxistas são sempre e imediatamente lidos como meros reprodutores de uma filosofia da história evolucionista e teleológica, acrescida da tão reducionista determinação de toda a sociedade a partir de bases econômicas, mesmo quando os próprios pensadores rejeitam esses pressupostos, ou quando os pensadores pós-estruturalistas são, sem mais, forçadamente inseridos dentro de uma corrente dita "pós-moderna", que pregaria o fim da possibilidade de qualquer tipo de ação política emancipatória e apenas a possibilidade de resignar-se niilisticamente diante da realidade social, mesmo quando autores como Butler (1995a) rejeitam explicitamente a subscrição dessas teses.
} 
Para tanto, partimos de uma inversão da ordem de exposição que estamos acostumados: originalmente, tratávamos de nossos objetos de pesquisa a partir do marco teórico da crítica marxista; agora, abordaremos o próprio marxismo como um objeto que passa a ser escrutinado com as lentes do pós-estruturalismo butleriano, sem, no entanto, conseguir abrir mão de nosso quadro teórico-cognitivo mais geral, que não pode ser plena e conscientemente despido por parte do pesquisador, como se fosse uma simples vestimenta. Mais especificamente, pretendemos realizar a tarefa de pensar o diálogo acima assinalado a partir de um exercício de deslocamento categorial que consideramos muito instigante: trata-se da proposta do comunismoqueer, elaborada no seio da ShTAB, a Escola de Teoria e Ativismo de Bishkek, organização política LGBTQIA+ (Lésbicas, Gays, Bissexuais, Transgêneros, Transexuais e Travestis, Queer, Intersexo, Assexuais e mais) localizada na capital do Quirguistão e cuja prática teórico-política tenta sintetizar as duas correntes críticas que protagonizam o diálogo que tentamos esboçar.

Nesse sentido, pretendemos, primeiramente, indicar elementos gerais e centrais da teoria pós-estruturalista elaborada principalmente por Butler, com apenas breves referências ao campo mais geral do pós-estruturalismo, uma vez que, por um lado, as reflexões da autora chamaram com mais ênfase nossa atenção e, por outro, sua influência nos círculos de Bishkek e explícita e evidente. Depois, tentamos fazer uma breve recapitulação da crítica marxista, indicando suas versões mais débeis diante das críticas esboçadas por Butler - notadamente, as teses que subscrevem uma visão teleológica da história e uma explicação economicamente determinista da sociedade -, para, então, indicar pesquisas marxistas contemporâneas cujo diálogo com a obra butleriana pode se mostrar mais salutar, uma vez que embasadas menos em um normativismo e mais em um ímpeto desnaturalizador das formas sociais capitalistas.

Por fim, traremos a experiência do coletivo ShTAB como uma materialização da possibilidade desse diálogo, principalmente a partir de como sua proposta do comunismo-queer combina: 1) um marxismo de recorte crítico e profundamente desnaturalizante; 2) uma releitura do soviético por meio do resgate do imaginário de dissidentes que se colocavam a favor do comunismo e de suas promessas ainda não 
cumpridas; e 3) uma abordagem do pós-estruturalismo butleriano e da teoria queer a partir de uma radicalidade política que pretende superar os essencialismos identitários. Cremos que se trata de um grupo de pensamento de profunda relevância e atualidade, uma vez que expressa a partir de vozes geralmente silenciadas e esquecidas no cenário acadêmico internacional (pense-se aqui na posição subordinada ocupada pelo Quirguistão em relação à Rússia e pela própria Rússia no sistema-mundo como um todo), uma leitura crítica e inovadora de uma tradição teórica de longa duração (o marxismo), conectando-a com lutas contemporâneas das pessoas LGBTQIA+, de modo a dar continuidade a uma genuína filosofia da práxis.

Por conseguinte, estamos diante de uma pesquisa de caráter exploratório, majoritariamente centrada em suscitar reflexões e questionamentos teóricos. Para tanto, utilizamo-nos de uma metodologia clássica de revisão bibliográfica, cuja seleção de textos foi primeiramente inspirada pelas indicações da disciplina acima mencionada e pelas nossas anteriores incursões em investigações sobre a crítica marxista, voltadas especialmente a questionar as interpretações evolucionistas, economicistas e normativas do marxismo. Depois, aproximamo-nos da experiência de Bishkek a partir de textos de suas principais lideranças intelectuais (notadamente, Georgiy Mamedov e Oksana Shatalova), tendo como pano de fundo alguns relatos, reportagens e notícias sobre a formação e atuação da ShTAB. Reiteramos, no entanto, a particularidade do tipo de leitura que pretendemos realizar: uma investigação crítica e aberta ao deslocamento de sentido e ressignificações de cada texto, em estreita conexão com a prática política dos movimentos sociais emancipatórios de nossos tempos.

\section{CORPO, DISCURSO E PERFORMANCE: O PÓS-ESTRUTURALISMO BUTLERIANO COMO RESPOSTA RADICAL AOS IDENTITARISMOS ESSENCIALISTAS}

Iniciamos nossa discussão a partir do termo "pós-estruturalismo", cujo significa exige uma admoestação que nos afaste de uma delimitação homogênea e generalista dessa expressão. Trata-se, a rigor, de uma categorização oriunda especialmente dos espaços acadêmicos estadunidenses cujo principal propósito era o de agregar vários filósofos franceses que compartilhavam uma série de influências em comum: a crítica 
do humanismo transcendental pautado na ideia de sujeito plenamente soberano e orientado por uma consciência fundada na razão e na autonomia do intelecto; a genealogia nietzscheana; as descobertas da psicanálise e sua ênfase no inconsciente; as demandas rebeldes levantadas no Maio de 68 francês, entre outras. Portanto, estamos lidando com um "termo de conveniência" que congrega vários autores marcados também por muitas diferenças epistemológicas e políticas (HOY, 2004, p. 17).

Nesse sentido, não nos propomos a avaliar a obra de todos os autores que compartilham as influências acima delineadas (o que poderia incluir nomes que vão de Lyotard a Foucault, de Derrida a Deleuze e de Baudrillard a Guattari), mas sim a abordar como esse conceito e proposta ganham vida a partir de uma filósofa estadunidense dotada de relevância para o tempo presente: Judith Butler.

Como pressuposto, subscrevemos a tese de Rodrigues (2019, p. 69-70), segundo a qual é impossível separar o pensamento butleriano em certas fases de seu pensamento: uma primeira voltada à discussão de gênero e à teoria queer (simbolizada em 1990, com a publicação de Gender Trouble) e uma segunda, preocupada com discussões mais gerais da temática da filosofia política em geral. Em verdade, Butler sempre transita entre essas duas influências e busca tirar frutos para essas duas "questões" de modo simultâneo e profundamente entrelaçado ${ }^{3}$.

Por certo, seria impossível sequer apresentar coerentemente toda a trajetória dessa autora em um espaço tão reduzido. Portanto, limitamo-nos a apontar como sua teoria pode contribuir para pensar as tarefas da crítica de maneira radical e sofisticada, a fim de ampliar nosso campo de análise e colocar em xeque as certezas com as quais operamos o nosso pensar e nosso agir.

Hegemonicamente, a teoria crítica no contexto brasileiro associa-se aos postulados gerais da Escola de Frankfurt, de modo a ter como seu ensaio fundante o

\footnotetext{
${ }^{3}$ Sua crítica à divisão entre gênero e sexo como um resquício de racionalismo iluminista que excisa radicalmente natureza e cultura, consciência e matéria, sujeito e objeto, por exemplo, bebe diretamente nas fontes da crítica pós-estruturalista do sujeito transcendental e soberano dotado de autoconsciência (RODRIGUES, 2019, p. 62). Por outro lado, suas discussões mais atuais de filosofia política trazem sempre em conjunto preocupações clássicas do debate da teoria feminista, como a importância do corpo, e procuram pensar como as violências gerais também afetam especificamente a existência das mulheres e de outros grupos atravessados por marcadores sociais de diferença que implicam uma distribuição desigual de condições de precariedade (RODRIGUES, 2019).
} 
Teoria Tradicional e Teoria Crítica, de Max Horkheimer, cujo principal intento é o de rejeitar a possibilidade de separar rigidamente o cognitivo e o normativo, os juízos de fato e os de valor, sujeito e objeto, entre outros, na construção de uma ciência social ${ }^{4}$. Por certo, isso implica a aceitação de que toda teoria traz em si certa carga normativa preocupada em dizer como o mundo deveria ser ${ }^{5}$.

No entanto, poderíamos dizer que esse insight será lido, a grosso modo, de duas maneiras no cenário contemporâneo: ou a partir de uma ênfase na necessidade de elaborar postulados normativos (que podem ser fundamentados a partir de noções abstratas, a-históricas e universais, ou mesmo a partir de uma leitura da história como progresso de certas categorias ${ }^{6}$ ), ou a partir de uma constatação da inseparabilidade entre as esferas do saber e do poder, o que abre espaço para questionar as certezas epistemológicas e os valores entranhados na nossa sociabilidade como elementos transitórios, socialmente estabelecidos e, portanto, abertos à contingência ${ }^{7}$.

Como esperamos que fique explícito no decorrer do presente texto, o sentido da crítica em Butler, a partir de um resgate especialmente embasado em Foucault e na genealogia, aproxima-se muito mais do segundo ponto. Ou seja, não evoca um normativismo abstrato, mas sim a desnaturalização das certezas de nossa teia epistemológica e dos discursos que constituem a nossa subjetividade e nossos modelos de pensar e de agir, de modo a evitar uma separação estanque entre saber e poder, descrever e prescrever, conhecer e transformar, ciência e política ${ }^{8}$ (BUTLER,

\footnotetext{
${ }^{4}$ Nesse sentido, Cf. especialmente HORKHEIMER, 1975, p. 139-140.

5 "A Teoria Crítica tem como ponto fundamental mostrar como as coisas são - objetivo de uma teoria -, porém a partir da perspectiva de como deveriam ser", logo "fazer teoria crítica significa que só posso entender o mundo a partir do que ele poderia ser" (LUDWIG, 2006, p. 151-153).

${ }^{6}$ Essa vertente contemporânea mais normativamente construída pode ser representada principalmente a partir das obras de Jurgen Habermas e de Axel Honneth. Para uma contextualização crítica dos posicionamentos desses autores e sua conexão também com uma ideia eurocêntrica de progresso, $\mathrm{Cf}$. ALLEN, 2016). A consideração dos limites desse normativismo é compartilhada pela própria Butler, quando, por exemplo, ela expõe a não criticidade de Habermas em relação a seu próprio conceito de normatividade (BUTLER, 2013, p. 161-162)

${ }^{7}$ Nesse segundo caso, a ênfase reside no ato de indagar e enfrentar "o que é pressuposto, certo, senso comum ou dado dentro da ordem atual das coisas" (BROWN, 2009, p. 8). Aqui, repensar-se-ia "a crítica como a prática na qual pomos em questão os limites de nossos modos de conhecimentos mais certos", em um processo que escancare os "domínios inteiros de ininteligibilidade" engendrados pelas categorias que interiorizamos e permita o "esgarçamento do tecido de nossa rede [web] epistemológica" (BUTLER, 2013, p. 163-164).

${ }^{8} \mathrm{Um}$ bom exemplo de como Butler interioriza essa constatação em sua obra apresenta-se no seu debate com Talal Asad, sobre a liberdade de expressão dentro do contexto do secularismo. Desde o
} 
2013). Consequentemente, o papel da crítica butleriana é o de mostrar "como o nosso conhecimento é organizado por esquemas históricos específicos" e delimitar "as condições de possibilidade para o conhecimento e o julgamento", bem como as "condições históricas de possibilidade para a resposta afetiva e avaliativa", que são todas construídas dentro de um jogo de poder e de uma relacionalidade social específica (BUTLER, 2009, p. 114-115).

Assim, adota-se uma postura antiessencialista, que, longe de ver o humano a partir de lentes metafísicas, ressalta a contingência de sua formação, a qual se dá repetida e sucessivamente pelo jogo político e pelo/no discurso. Nesse tom é que se repete a crítica do sujeito transcendental, que, na filosofia europeia moderna, naturaliza e toma como certo e incontornável o "conceito ocidental do indivíduo proprietário de si presumidamente livre de todas as formas de coerção" (BROWN, 2009, p. 14-15). No entanto, essa construção do sujeito soberano e plenamente consciente, que age na política de forma autointeressada e com o controle de todos os cenários, está muitíssimo longe de ser algo natural; trata-se, em verdade, de algo constantemente construído social e discursivamente.

Ou seja, para aderir aos requisitos necessários para ser lido e poder agir como esse sujeito transcendental que é visto "ontologicamente como condição de possibilidade da ação, linguagem, política, etc.", as pessoas devem reiteradamente repetir as demandas de certas estruturas discursivas que as constringem a aderir a certas práticas e identidades para serem validadas dentro dos jogos de poder imperante $^{9}$ (FONSECA, 2019).

início, a filósofa reconhece que "não faria sentido dizer que descrição e prescrição são empreitadas absolutamente distintas". Por isso, julga mais interessante avaliar os próprios modos de avaliação normativa e mostrar que "toda descrição já está comprometida com um modelo avaliativo", reforçando a intuição levinasiana de que as "normas precedem a descrição" (BUTLER, 2009, p. 104-105). No fim, essa própria noção é retomada para constatar que a própria teoria de Asad, que se pretende meramente comparativa, traz um "forte reivindicação [claim] normativa", na medida em que ele se mostra "chocado e indignado [outraged] pela nossa falta de choque" com a violência colonial, enquanto nos chocamos com os protestos muçulmanos contra representações desrespeitosas de Maomé na mídia europeia (BUTLER, 2009, p. 107-108).

${ }^{9}$ Eis aqui justamente uma descrição precisa da noção de performatividade em Butler, de modo a expressar sua explicação não-metafísica da experiência de construção das subjetividades: "Pela performatividade é possível uma compreensão dos sujeitos que se realizam de modo continuado, no lugar de sujeitos vistos ontologicamente como condição de possibilidade da ação, linguagem, política e etc. Menos que uma rejeição radical do sujeito, a performatividade aponta para a mobilidade de sua 
Contudo, isso não implica em completa determinação e impossibilidade de agência, visto que a própria necessidade de reiterar e repetir o discurso abre a própria condição da agência, uma vez que, nesse desenrolar, é possível perceber a resistência intersticial construída a partir das possibilidade de retrabalhar, reordenar e ressignificar as categorias que nos cercam, de modo a operar um deslocamento de sentido nessas categorias, de acordo com uma certa normatividade que pode se opor radicalmente à que originou esse mesmo processo de categorização (BUTLER, 1995b, p. 135-137). Somente assim, por exemplo, é possível explicar como a Revolução Haitiana pôde apropriar-se de uma visão fundacionalista de subjetividade e, na sua reoperação, reivindicar uma noção de universalidade e igualdade que extrapolava os contornos originários de um conceito europeu, branco e escravista (BUTLER, 1995b, p. 141).

Desse modo, Butler consegue rejeitar, em uma só tacada, tanto a ideia de um sujeito soberano quanto a redução da existência humana a mero estruturalismo que nos condenaria a repetir os desígnios da base estrutural da sociedade, sem qualquer possibilidade de agência. Aqui, poderíamos adicionar, encontramos um refinado debate sobre os caminhos de ressignificação desses termos e os riscos de repeti-los acriticamente. Por isso, é necessário reconhecer que, em práticas concretas de resistência, nunca nos deparamos com a possibilidade de separarmo-nos completamente das concepções metafísicas que atravessam certas construções discursivas (como a noção de "presença" ou de "sujeito de direito"), mas também nunca estamos integralmente subsumidos de antemão à força e influência desses conceitos (BUTLER; ATHANASIOU, 2013, p. 14).

Portanto, a crítica aqui esboçada opera a partir de outro registro teórico: o de resgatar e escutar as vozes historicamente invisibilizadas, as outras possibilidades de sentido que foram soterradas pelas construções hegemônicas de poder, as outras noções de personalidade que, derrotadas na disputa política - que, nunca é demais lembrar, extrapola os limites do Estado soberano, localizando-se em redes complexas

inscrição enquanto fundamento que se recoloca incessantemente e por isso já não se constitui a partir de uma significação forte e metafísica" (FONSECA, 2019). 
de relações que permeiam nosso cotidiano -, não foram consideradas dignas de serem vividas.

Em suma, podemos destacar aqui a preocupação butleriana com uma crítica que assume um embasamento ético-político não fundado em conceitos metafísicos e abstratos, mas sim em uma noção de interdependência e de responsabilidade com o outro. Cumpre asseverar, todavia, que não nos referimos ao outro como mero espelho de nossa própria identidade/igualdade; essa noção deve ser entendida mais como o radicalmente outro, de modo a abarcar aqueles modos de vida que expressam o indizível, o socialmente ininteligível para os padrões dominantes de conhecer e agir, de modo a contestar o próprio entendimento de nós mesmos (BUTLER, 1995b, p. 142143).

A partir dessa consideração é que Butler consegue abrir seu campo de análise para dar centralidade aos grupos sociais em situação de precariedade como um todo. Assim, sua teoria crítica preocupa-se com a corporalidade e existência concreta daquelas pessoas e grupos que se encontram diante de uma exposição diferenciada e politicamente induzida a situações de injúria, violência, pobreza, morte e condições indignas de vida, de modo a expressar uma dispensabilidade de sua vida e também um menor merecimento de luto em relação à sua morte (BUTLER; ATHANASIOU, 2013, p.19).

Desse modo, podemos aludir algumas implicações políticas dessa passagem do campo do sujeito transcendental para o dos corpos concretos em situação de precariedade: 1) há, aqui, a construção de uma política dos corpos que enfatiza a interdependência entre eles para a constituição de suas condições de florescimento ${ }^{10}$;

\footnotetext{
${ }^{10}$ Ou seja, a noção de corpo de Butler não é a ficção eurocêntrica da propriedade individual do próprio corpo (que podemos encontrar principalmente a partir de John Locke), mas sim uma ontologia social, que reconhece a interdependência dos corpos individuais em relação a um conjunto de relações que permitem a sua manutenção e florescimento. Assim, "To see the body as social and relational - an assemblage rather than a monad - is also to understand that our bodies carry around layered histories written in our genetic makeup, our cultural memories, our psychic wounds, and all the imprints on us of race, class, gender, and sexual difference. These imprints paradoxically inform the ways we are able to move, or not, in public space and to assert ownership over our bodies at the same time as they limit our capability to do so" (PETCHESKY, 2015, p. 264-265). Assim, "o corpo deveria ser entendido [...] nos termos das redes de relações que o apoiam", de modo a reconhecer sua "dependência de outros corpos e de redes de apoio", uma vez que "o corpo é inserido na vida social antes de mais nada em condições de dependência", como, por exemplo, a capacidade de alimentar, abrigar e mesmo aprender a comunicar-se com os outros (BUTLER, 2018, p. 118-119).
} 
2) enfatiza-se, enfim, a dimensão performativa (lembrando-se que performatividade sempre indica uma "relação cruzada entre corpo e linguagem" [BUTLER, 2018, p. 125]) e reiterativa que assola os corpos humanos, que são exigidos uma repetição de atos específicos para conseguir atingir o status de sujeito ${ }^{11}$.

Para finalizar essa seção, gostaríamos de indicar a radicalidade imediatamente discernível na proposta teórica de Butler, ao menos no sentido de que suas proposições não significam uma adesão às teses do fim da história, ou uma repetição dos traçados lyotardianos, que se fundam na incredulidade em relação à possibilidade de qualquer metanarrativa ${ }^{12}$, ou mesmo um pós-modernismo da resignação, como diria Sousa Santos (2002). Pelo contrário, a autora se posiciona diante das mais encarniçadas lutas do tempo presente, de modo a denunciar as práticas bárbaras de violência, exclusão e dominação que se cristalizam a partir da sociabilidade e racionalidade neoliberal ${ }^{13}$.

Nessa esteira, deparamo-nos com elementos suficientes para indagar, a partir da leitura do legado da crítica marxista, se haveria a possibilidade de identificar elementos mais próximos da crítica butleriana. Na próxima seção, tentamos nos aproximar dessa pergunta a partir de um resgate mais geral e abstrato do marxismo e da obra de Marx, para, na última, abordar esse questionamento a partir da práxis concreta da proposta do comunismo-queer nascida em Bishkek.

\section{A CRÍTICA MARXISTA PARA ALÉM DA TELEOLOGIA E DO DETERMINISMO: POSSIBILIDADES DE DIÁLOGO COM AS INQUIETAÇÕES DE BUTLER}

\footnotetext{
${ }^{11}$ Para uma leitura sobre a ligação entre precariedade e performatividade em Butler, Cf. MARINHO, 2020, p. 126-127.

${ }^{12}$ Para maiores detalhes, Cf. LYOTARD, 1984, p. xxiv e ss.

${ }^{13}$ Aqui, percebe-se "a crescente influência do trabalho de sua companheira, Wendy Brown", nos textos de Butler (RODRIGUES, 2019, p. 70) e a sua maior preocupação em desvendar "uma nova forma de combate à governamentalidade neoliberal" (MARINHO, 2020, p. 126). Portanto, suas posições albergam-se na refinada análise de Brown (2015 e 2016) sobre o funcionamento do neoliberalismo a partir da noção de poder e de governamentalidade em Foucault. Trata-se, enfim, de uma seara importante de análise para o pensamento crítico, que foi seguida também por outros autores, como Laval e Dardot (2016), os quais, é curioso ressaltar, realizam também uma síntese entre a tradição teórica foucaultiana e os legados da crítica marxista.
} 
De largada, é necessário reconhecer que, de acordo com a leitura predominante de Marx na academia brasileira e internacional - muito mais influenciada por pós ou mesmo anti-marxistas -, os elementos acima descritos teriam muito pouco a ver com a crítica marxista, uma vez que esta estaria incontornavelmente conectada a uma teleologia histórica de progresso unilinear e profundamente celebratória de todas as promessas eurocêntricas e coloniais da modernidade ${ }^{14}$ (incluindo aqui a ideia de um sujeito transcendental, de uma ciência capaz de compreender perfeitamente a nossa realidade exterior e de uma ação política consciente que se libertaria completamente de ideologias, afetos e quaisquer influências inconscientes), bem como também aderiria a modelos explicativos da sociedade a partir de contornos marcados por um determinismo econômico, no qual todos os aspectos culturais e não econômicos seriam meros epifenômenos cuja explicação e sentido poderiam ser encontrados apenas na esfera fundamental/estrutural de existência social: a economia ${ }^{15}$.

Por certo, essas interpretações da obra de Marx e de seu legado não são puramente aleatórias: elas expressam, de fato, uma interpretação do corpus da obra marxiana, notadamente a do marxismo-leninismo como ideologia de estado da URSS, a partir principalmente da ascensão de Stálin ao poder. No entanto, essa leitura, baseada pesadamente em um prefácio que não ultrapassa sequer a marca de dez páginas $^{16}$, já foi amplamente questionada e revisada a partir de novos rumos das investigações marxistas sobre a obra de Marx, a partir principalmente da publicação

\footnotetext{
${ }^{14}$ Para uma crítica dessa visão unilinear de progresso e de celebração da modernidade, a partir da noção de colonialidade do poder (divisão do mundo a partir dos marcadores sociais de raça e a atribuição de certas formas de trabalho e de vida a cada uma delas) e da profunda interconexão entre modernidade e colonialidade, Cf. QUIJANO, 2005.

${ }^{15}$ Nesse sentido, para expressar esse discurso, podemos citar como exemplo as seguintes palavras de Sousa Santos: "Marx não se limitou a apresentar uma macro-análise do capitalismo; formulou, ainda que de modo não sistemático, uma nova teoria da história, o materialismo histórico, nos termos da qual as sociedades evoluem necessária e deterministicamente ao longo de várias fases, segundo leis que muito sumariamente podem ser formuladas do seguinte modo: o nível de desenvolvimento das forças produtivas (o nível de desenvolvimento tecnológico e da produtividade do trabalho, etc.) determina e explica o conjunto das relações sociais de produção, ou seja, a estrutura econômica da sociedade; por sua vez, a estrutura econômica da sociedade, a chamada 'base econômica', determina e explica as formas políticas, jurídicas e culturais que dominam na sociedade, ou seja, a 'superestrutura"' (SOUSA SANTOS, 1999, p. 36).

${ }^{16}$ Aqui, referimo-nos ao Prefácio à Contribuição à Crítica da Economia Política, publicado em 1959 (MARX, 2008).
} 
de seus trabalhos filosóficos e preparatórios d'O Capital, que permitiriam, como diria Dussel (1988), a descoberta de um "Marx desconhecido", que vem à tona principalmente de um conglomerado de pesquisadores próximos do projeto editorial histórico-crítico do MEGA (Marx-Engels-Gesamtausgabe) de Marx e Engels, voltado à publicação completa de suas obras ${ }^{17}$.

A partir daí, poderíamos indicar, na maioria dessas novas análises, uma negação da noção de um evolucionismo unilinear, em especial a partir do Marx tardio, que, após a publicação da primeira edição d'O Capital, interessou-se profundamente no estudo de sociedades pré-capitalistas e, particularmente, mostrou muita atenção em torno da mobilização dos populistas russos contra a autocracia tsarista. Nesse contexto, rejeitou expressamente a elaboração de "uma teoria histórico-filosófica do curso geral fatalmente imposto a todos os povos, independentemente das circunstâncias históricas nas quais eles se encontram", bem como negou que sua obra pudesse ser lida como uma "teoria histórico-filosófica geral, cuja virtude suprema consiste em ser supra-histórica"18 (MARX, 2013a, p. 68-69).

Desse modo, emergem interpretações do legado marxiano muito mais condizentemente dialogáveis com a crítica butleriana, uma vez que elas, a partir de uma leitura atenta d'O Capital e de seus estudos preparatórios, descrevem a empreitada marxiana como uma atividade de exposição da natureza histórica e socialmente construída das formas sociais tecidas no desenrolar da sociabilidade capitalista $^{19}$. Aqui, não haveria espaço para descrições genéricas e generalistas sobre os rumos de todas as sociedades, mas sim um esforço concreto de estudo de uma

\footnotetext{
${ }^{17}$ Para uma coletânea recente que envolve pesquisas desse gênero e com releituras interessantes da obra de Marx, Cf. MUSTO, 2019.

18 Para analisar com mais detalhes leituras recentes que tentam abordar esse aspecto da obra marxiana, Cf. ANDERSON, 2010, e MUSTO, 2018.

19 "A forma de valor do produto do trabalho é a forma mais abstrata, mas também mais geral do modo burguês de produção, que assim se caracteriza como um tipo particular de produção social e, ao mesmo tempo, um tipo histórico. Se tal forma é tomada pela forma natural eterna da produção social, também se perde de vista necessariamente a especificidade da forma de valor, e assim também da forma-mercadoria e, num estágio mais desenvolvido, da forma-dinheiro, da forma-capital etc." (MARX, 2013b, p. 1133). Nesse sentido, como aponta um importante arquivista das obras de Marx e um dos representantes dessas novas leituras, "Critique aims to break down the theoretical field (meaning the self-evident views and spontaneously arising notions) to which the categories of political economy owe their apparent plausibility; the 'absurdity' (Verrücktheit) of political economy should be made clear" (HEINRICH, 2012, p. 35).
} 
situação concreta, marcada pelo ímpeto de desnaturalizar as formas sociais capitalistas e indicar a possibilidade de transformá-las.

Essas condições de transformabilidade, no entanto, não serão concretizadas a partir do gênio intelectual de algum teórico que captaria perfeitamente a dialética da realidade e suas leis históricas gerais e imutáveis. A teoria de Marx, de acordo com o entendimento que propomos, não é um normativismo nos moldes habermasianos mesmo porque o próprio Marx sempre se negou a "prescrever receitas para os caldeirões do futuro" -, mas uma proposta de conexão com os movimentos de emancipação de seu tempo ${ }^{20}$, com ênfase, em especial, na práxis de libertação do movimento operário ${ }^{21}$. Desse modo, podemos entender que o mais precioso de sua obra consiste em delinear uma filosofia da práxis que pretende aprender com a mobilização de grupos oprimidos e marginalizados e que, no fim das contas, rechaça uma separação rígida entre teoria e prática, ciência e política, saber e poder, aprender e ensinar. A única forma de ultrapassar essas dicotomias consistiria em considerar que "a coincidência entre a altera[ção] das circunstâncias e a atividade ou automodificação humanas só pode ser apreendida e racionalmente entendida como prática revolucionária" (MARX, 2007, p. 534). Por meio dessa leitura, nos afastamos daquela versão do marxismo que prega um conhecimento fechado e supra-histórico da realidade e aproximamo-nos de uma crítica aberta à exterioridade dos grupos sociais lidos como inequivocamente outros e cujas demandas nos interpelam a transformar radicalmente a realidade para além das normatividades pré-concebidas pelo intelecto dos filósofos. Nessa interpretação, a crítica marxiana não seria um regresso à arché grega, o ócio dos cidadãos atenienses ou à tradição em geral ${ }^{22}$, mas

20 Poderíamos citar, de forma não extensiva, os seguintes processos de resistência que foram acompanhados por Marx: 1) o movimento de seitas operárias na França; 2) as revoltas camponesas na Alemanha; 3) o movimento sindicalista e cartista na Inglaterra; 4) a revolução agrária na Irlanda e a organização dos trabalhadores irlandeses; 5) a luta pela abolição da escravidão nos EUA; 6) as práticas de resistência anticolonial na China e na Índia; 7) a experiência da Comuna de Paris; 8) a organização da Internacional dos Trabalhadores; e 9) a mobilização dos populistas russos, que propunham começar a construir o socialismo a partir das comunas rurais.

21 Para um cuidadoso estudo sobre o imenso significado que o contato com o proletariado e seu movimento político tiveram no florescimento da teoria de Marx, Cf. LOWY, 2012.

22 As provocações que classificam a obra de Marx dessa maneira encontram em ARENDT, 1961, p. 18-25. Por certo, o argumento por ela empregado traz importantes nichos de leitura para entender e problematizar algumas frases marxianas, em especial se concatenadas com o que se chama de "era moderna" e seu relacionamento paradoxal e ambíguo em torno da tradição. No entanto, temos que 
sim práxis fundamentada na imanência, contingência e criatividade dos movimentos de contestação de seu tempo.

Por certo, não sugerimos aqui um encontro imediato e harmonioso com as propostas, que poderíamos chamar de pós-estruturalistas, de Butler (há, de fato, tensões e escolhas teóricas que não podem ser tratadas como inexistentes), mas sim a constatação de que o marxismo, apesar de ser uma vertente de teoria crítica que não deixa de operar em um registro diferente, não está marcado por uma impossibilidade incontornável de diálogo, uma vez que certas leituras de seus textos mostram-se condizentes com vários dos insights esboçados na seção anterior.

Assim, como uma possível síntese provisória, poderíamos pensar o marxismo contemporâneo como uma proposta que pretende operar para além da dicotomia micro-macropolítica. Desse modo, reconhece-se que essas empreitadas recusam um pós-modernismo da resignação, que colocaria como central em seu pensamento o rechaço a toda forma de metanarrativa ou de lutas que possam ir além de cada miscrocosmo particular, mas sem deixar de lado a possibilidade de uma abertura de diálogo com reflexões críticas da transcendência metafísica de narrativas, uma vez que essa leitura transcendental/teológica criticada de fato reduz as disputas concretas a grandes modelos abstratos de normatividade. Em especial, cremos que a conversa é especialmente profícua quando essa crítica, como a de Butler, está amparada na responsabilidade ética de visibilizar e ouvir grupos sociais localizados em situações de precariedade, as quais são social e desigualmente distribuídas.

Aqui, há, em verdade, a intenção principal de conectar essas duas dimensões (do micro e do macro, do local e do global, da parte e do todo), em vez de indicar, por um lado, a impossibilidade da macropolítica ou, por outro, a inutilidade da

indicar também a incapacidade das proposições arendtianas de lidar com as leituras de Marx, por exemplo, que enfatizam o surgimento do trabalho vivo como um espaço de exterioridade radical à sociabilidade do capital e cujos movimentos não podem jamais se reduzir a uma simples volta ao passado, porque inspirada e enraizada na prática do movimento operário (Cf. DUSSEL, 1988). Além disso, a própria categoria "trabalho" em Marx realiza flutuações entre seu sentido enquanto forma social particularmente engendrada pela generalização da forma-valor e seu sentido enquanto práxis material que se realiza em todas as sociedades. Assim, a abolição do trabalho só pode ser compreendida tomando em conta a primeira dimensão e refazendo todo o esforço de concatenação das formas sociais (mercadoria, troca, dinheiro, valor, mais-valor, etc.) especificamente atreladas às relações sociais capitalistas. 
micropolítica. Destarte, a única forma de realizar essa ligação residiria, justamente, na possibilidade de estreitar laços político-teóricos com os movimentos críticos de resistência e de contestação da ordem que emergem em nosso tempo, de modo a enfatizar a dimensão sempre autocrítica e permanentemente rediscutível da práxis ${ }^{23}$.

Se, com as linhas acima, acreditamos ter demonstrado alguns caminhos de diálogo a partir de um panorama muito geral, cumpre ainda, para sermos coerentes com a crítica a uma política fundacionalista abstrata, concretizar essas reflexões a partir de casos e experiências concretas. Assim, na próxima seção, deparamo-nos com uma oportunidade ainda maior: a de perceber como o desenrolar desse debate se deu a partir dos espaços de ativismo do denominado comunismo-queer de Bishkek.

\section{O COMUNISMO-QUEER A PARTIR DOS DIÁLOGOS DE BISHKEK}

A proposta do comunismo-queer, que aqui reverberamos, ${ }^{24}$ foi originalmente concebida na capital do Quirguistão, um país pós-soviético localizado na Ásia Central e dotado de inserção periférica dentro de uma zona de influência que já era inserida de maneira subordinada na economia e geopolítica mundial ${ }^{25}$. Particularmente, tratase de formulação estreitamente relacionada a um contexto pós-soviético, no qual se destacam dois rumos conjunturais importantes: 1) a destruição do legado de proteção social da URSS e a sua substituição por um avanço de reformas neoliberais de gestão

\footnotetext{
${ }^{23}$ Um bom exemplo de proposta que consegue conjugar essas duas dimensões é a proposta de práxis instituinte do comum, elaborada por Laval e Dardot (2017) como resposta à racionalidade globalizante e totalizante do neoliberalismo. Essa proposta enfatiza o comum como um ato consciente de instituição do inapropriável, que, concomitantemente: 1) aglutina pessoas envolvidas em uma mesma atividade (co-atividade); 2) de forma recíproca e democrática, institui as regras (incessantemente renovadas, sempre instituintes e nunca instituídas de forma inerte ou necrosada) de uso de um bem comum; e 3) gesta relações de co-obrigação entre uma coletividade que se produz por meio de sua própria práxis política autônoma.

${ }^{24}$ Cumpre indicar, no entanto, que essa proposta não é necessariamente a pioneira em correlacionar o marxismo ou o comunismo com pautas de grupos marginalizados por sua sexualidade. Por exemplo, Mario Mieli, intelectual gay e comunista italiano cuja produção teórico-política localiza-se entre as décadas de 1970 e 1980, já escreveu vários ensaios a partir dessa tentativa de conexão, que foram compiladas no livro Por um comunismo gay: elementos de crítica homossexual (MIELI, 2018). No entanto, escolhemos a proposta quirquistânesa por sua proximidade explícita com contribuições de Butler e por seu envolvimento em movimentos concretos de luta política.

${ }^{25}$ Essa interpretação sobre a Rússia e a União Soviética como a história de um império periférico, a partir da influência da teoria do sistema-mundo de Wallerstein e outros pensadores, pode ser encontrada em KAGARLITSKY, 2008.
} 
da economia e da vida das pessoas (KAGARLITSKY, 2018, p. 304-322 e SOLOMKO, 2017); 2) sob a égide da influência russa, uma ofensiva conservadora contra os direitos de grupos LGBT e a favor de "valores tradicionais" ${ }^{26}$, que implica na violação de direitos já muito denunciada por ONGs internacionais ${ }^{27}$.

Dentro desse ambiente histórico surgiu, no início da segunda década do século XXI, a Escola de Teoria e de Ativismo de Bishkek (Школа Теории и Активизма Бишкек), conhecida por sua sigla ShTAB (ШTAБ). Apesar de seu curto ciclo de duração ${ }^{28}$-- pouco menos de uma década -, essa empreitada chamou a atenção de intelectuais e ativistas no mundo inteiro ${ }^{29}$, a partir de suas produções bibliográficas, arquivísticas e artísticas, das quais poderíamos destacar, no primeiro campo, os

26 “En 2013, el parlamento ruso aprobó una ley sobre la «propaganda gay» que señalaba el programa LGBT como el principal antagonista de los 'valores tradicionales', cuya defensa y promoción a nivel global la Rusia de Putin ha asumido como propias. Kirguistán es uno de los países exsoviéticos más leales a Rusia. Muchos y muchas de sus habitantes reciben la información a través de los medios rusos y el político más popular en el país es Vladímir Putin. Así pues, no es precisamente una sorpresa que en Kirguistán la homofobia política de la televisión rusa se haya trasladado de manera bastante rápida a la vida real. En el otoño de 2013, las autoridades prohibieron la proyección de la película Soy gay y musulmán en el festival por los derechos humanos Bir Duino [Um só mundo] y, a comienzos de 2014, los diputados kirguises ya estaban preparando el borrador de su propia ley sobre la "propaganda gay"' (MAMEDOV; SHATALOVA, s. d.).

27 Mas, como veremos a seguir, os ativistas quisguistaneses que reverberamos não aceitam acriticamente os discursos de direitos humanos eurocentricamente embasados, na medida em que estes, com uma mão, oferecem ajuda e auxílio, mas, com a outra, tiram as bases sociais e os enraizamentos não fundados na abstração do sujeito de direito que reivindica seus direitos como proprietário de si mesmo e mônada isolada (Cf. SEGATO, 2012). Cumpre indicar que Butler também é crítica desse discurso eurocêntrico dos direitos humanos que, de um lado, reivindica causas justas, mas primariamente com a intenção de pintar o outro como intolerante, indigno e selvagem, de modo a justificar intervenções humanitárias e espoliações, tal como faz o governo de Israel a partir de sua práticas de pinkwashing (BUTLER, 2018, p. 66).

28 "ShTAB itself had ended in the form in which I encountered it a few years earlier-Mamedov had left the group, which was reorganising itself into FEMShTAB, a specifically feminist organisation, while Mamedov was now working for Labrys, an LGBT campaign group in Bishkek, and was abandoning art altogether. On forming, ShTAB had, he told me, a precise plan. First they would aim to understand Soviet Central Asia - first through Utopian Bishkek, a book and a series of maps on technological, proletarian, artistic and architectural utopias whose real traces could be found in the existing city, then through publications philosophical (Queer Communism as Ethics, published by the Free Marxist Press in Moscow), historical and post-colonial (the book Concepts of the Soviet in Central Asia), and then the final part of the plan, where they would move forward into the future, in Completely Different, an anthology of Queer Communist science fiction stories by Central Asian women. Their work as artists and provocateurs was done; what came next, was politics." (HATHERLEY, 2018).

${ }^{29} \mathrm{Um}$ indicativo disso é o fato dos principais documentos desse grupo terem sido traduzidos para inglês, espanhol e italiano. Por outro lado, é importante identificar que essas próprias práticas de tradução também indicam uma forma de ativismo e de mobilização política, ainda mais se considerarmos que a prática dos tradutores responsáveis por esses trabalhos rompe com os pressupostos clássicos de uma tradução "fiel", de modo a reconhecer a politicidade, contingência e o caráter construído e não transparente da linguagem. Para um relato sobre essa prática de tradução, Cf. SUYARKULOVA, 2019. 
manifestos em defesa de um comunismo-queer (Cf. ShTAB, 2015 e MAMEDOV; SHATALOVA, 2016) e suas releituras de autores soviéticos como "membros" dessa vertente (Cf. MAMEDOV; SHATALOVA, s. d. e MAMEDOV; SHATALOVA, 2017) e, no segundo, o resgate de imaginário comunista LGBTQIA+ na cidade de Frunze -- o nome de Bishkek durante o período soviético --, a partir da nomeada Comuna Aleksandra Kollontai, que, durante as décadas de 1960 e 1970, levantava a perspectiva derrotada de um comunismo outro, crítico dos padrões de gênero e de sexualidade reforçados pelo governo da URSS $^{30}$.

Assim, em seu primeiro manifesto, afirmam a sua proposta a partir de um entendimento delimitado do queer:

\begin{abstract}
Nós entendemos queer não apenas como a erosão [размывание] dos padrões de sexo, gênero e sexualidade, mas, no todo, como um desafio às políticas tradicionais de identidade em sua variedade essencialista, como a rejeição das fronteiras nacionais, raciais, étnicas e de gênero. Queer e comunismo são conceitos reciprocamente dependentes e necessários, são nomes de um processo que supera a alienação (ShTAB, 2015, p. 22).
\end{abstract}

Esse caráter mutuamente dependente é reforçado imediatamente no decorrer do texto, quando os próximos destinam-se, justamente, a argumentar que: por um lado, "ser queer significa ser comunista", porque o capitalismo aproveita-se da dominação patriarcal para aumentar as possibilidades de exploração e isso só tende a se agravar diante do avanço de modelos cada mais conservadores de neoliberalismo, que aliam a subjetividade do homem-empresa com noções tradicionais de família ${ }^{31}$; por outro, "ser comunista significa ser queer, na medida que

\footnotetext{
30 "A análise histórico-materialista das relações entre os sexos em diversas etapas do desenvolvimento das forças produtivas (antiga, feudal e capitalista) foi incapaz de conduzir a camarada Kollontai à legítima conclusão de que a própria exclusividade professada da atração emocional e erótica de homens em relação a mulheres e mulheres em relação a homens é também histórica e ideologicamente condicionada. A camarada Kollontai proclama o amor-camaradagem entre mulheres e homens, mas não poderia haver também um amor-camaradagem entre mulheres e mulheres e entre homens e homens?" (COMUNA A. M. KOLLONTAI, 2015, p. 200). Para um resgate histórico sobre o reforço a papéis tradicionais de gênero realizado a partir da influência do stalinismo na URSS, Cf. GOLDMAN, 1993.

${ }^{31}$ Essa tendência foi precocemente identificada já em Brown (2006), quando a autora analisava as gestões de George W. Bush. Esse processo, como se percebe, intensificou-se ainda mais e, com isso, identificamos a profusão de governos conservadores, ligados a grandes conglomerados econômicos e envolvidos em práticas cada vez mais violentas de espoliação de grupos pobres, racial, étnica e xenofobicamente excluídos, bem como mulheres e outras minorias de gênero e de sexualidade, etc.
} 
a construção de uma sociedade radicalmente outra (comunismo) não pode interminavelmente copiar a velha matriz edípica", de modo a ser necessário abandonar a resignação de parcela da esquerda em torno de temas voltados ao corpo e sexualidades marginalizadas, uma vez que "as pessoas não produzem apenas pessoas e coisas, mas também sentidos e afetos" e uma mudança radical não pode ser pensada sem incluir essas dimensões tão bem enfatizadas pela teoria queer (ShTAB, 2015, p. 22).

No entanto, os ecos da influência butleriana expressam-se mais precisamente quando Mamedov e Shatalova, importantes lideranças da ShTAB, descrevem a teoria queer como um "amplo campo de ideias e aproximações para o entendimento da corporalidade no contexto das relações sociais", no qual seria possível destacar, a grosso modo, três caraterísticas principais: 1) um radical antiessencialismo, que opera a partir da noção de "performatividade", atrelada à repetibilidade e executabilidade de certas estilizações corporais de acordo com normatividades e obrigações delineadas social e relacionalmente, a fim de demonstrar a construção social e discursiva de nossas identidades; 2) um esforço de articulação dos laços identitários com práticas e contextos de exclusão e estigmatização, visto que a construção essencialista da identidade implica a naturalização de certos modelos de subjetividade e, consequentemente, a criação de amplos de ininteligibilidade de modos e estilos de vida outros, além de práticas de exclusão e de distribuição desigual de bens e privilégios, de um lado, e de precariedade, de outro, de modo a beneficiar as identidades consideradas "normais" em detrimento das "desviantes"; 3) uma radicalidade ética e política, que, longe de contentar-se em identificar as práticas de dominação, invisibilização e reduções de experiências outras a uma normatividade vigente, reivindica que "essas condições podem e devem ser mudadas", de modo a não defender a simples normalização de práticas "desviantes" (na qual os movimentos LGBT seriam um outro integrado na ordem vigente), mas sim uma "política de coalizão das diferenças", que não seja pautada na identidade (no sentido de mesmidade e de nivelamento das diferenças) e na semelhança e que, portanto, busque enfocar as práticas sociais de movimentos em sua "diferença e especificidade": em suma, na 
contingência dessas diversas formas de estilização da vida (MAMEDOV; SHATALOVA, 2017, p. 114-117).

Posteriormente, Mamedov e Shatalova empreendem um instigante movimento: em vez de indicarem o rompimento da teoria queer com o marxismo soviético, preferem reivindicar para a sua teoria do comunismo-queer dois filósofos da União Soviética (Evald llitch llyenkov e Aleksandr Vasilevitch Suvorov). O primeiro, renomado leitor da obra de Marx e provavelmente um dos soviéticos mais difundidos nos círculos de filosofia marxista crítica do Ocidente, é lido a partir de sua filosofia educacional que enfatiza a construção completamente social da subjetividade humana e de nossas capacidades (rejeitando qualquer traço ou resquício de reducionismo biologista ou fisiológico); o segundo, psicólogo e filósofo surdo-mudo nascido na cidade de Frunze, por sua vez, repete as considerações acima delineadas e enfatiza a importância de compreensão dos corpos lidos como "descapacitados" a partir de outros modelos cognitivos que extrapolam os limites da psicologia dominante de seu tempo ${ }^{32}$ (MAMEDOV; SHATALOVA, 2017, p. 118-129).

Nesse sentido, o ponto de encontro assinalado pelos ativistas de Bishkek é o de um discurso crítico desnaturalizador do que tomamos como anterior à nossa própria constituição enquanto sujeitos, o que culmina, então, em uma teoria que consegue conjugar uma politicidade radical com uma postura rechaçadora de qualquer identitarismo essencialista. Aqui, emerge a proposta do diálogo com os grupos oprimidos ou em situação de precariedade como a principal fonte de uma prática política de resistência crítica capaz de pôr em xeque as certezas da teia cognitiva de nosso tempo. Consequentemente, retornamos a muitos pontos já abordados quando discutimos a obra de Butler, como: 1) a performatividade/reiteratividade no processo de subjetivação/sujeição dos sujeitos; 2) a precariedade a partir dos temas da exclusão e da estigmatização; e, por fim, 3) a ênfase na contingência do discurso, da política e das relações sociais, que implica a radicalidade como procedimento de desnaturalização de nossas certezas e reconhecimento da possibilidade de mudança do status quo.

32 Uma síntese de divulgação dessa pesquisa pode ser encontrada em MAMEDOV; SHATALOVA, s. d. 
Além disso, em sentido inimaginável para a maior parte de pensadores de uma esquerda que demoniza o dito "identitarismo", percebemos que o pensar da relacionalidade social empreendido pelos membros do ShTAB e por Butler deságua na percepção da insuficiência das ontologias identitárias. Há, na verdade, a reivindicação da "necessidade de uma luta mais generalizada contra a precariedade", a partir da responsabilidade ético-política de buscar uma vida igualmente possível de ser vivida e distribuição igualitária dos bens públicos (BUTLER, 2018, p. 65).

Logo, enfatizamos a queerness dessa teoria: sua estranheza, seu caráter desviante, seu sentimento de ser algo "fora do lugar", porque opera a partir do exercício de deslocamento de significados, de modo a resistir intersticialmente contra os sentidos hegemônicos de uma normatividade vigente ${ }^{33}$. Por isso, no título do presente trabalho decidimos nomear o comunismo-queer como um estranho encontro entre a crítica butleriana e a crítica marxista. Apenas abraçando esse aspecto da teoria queer é que se torna possível ouvir e identificar essa 'estranheza' na sua contingência, singularidade, diversidade e irrepetibilidade. Basta, por fim, rememorar que a própria Butler, em um contexto no qual indicava a necessidade de uma "ética de coabitação" para enfrentar as lutas contemporâneas, propôs que fosse recordado o seguinte postulado: "o termo queer não designa identidade, mas aliança, e é um bom termo para ser invocado quando fazemos alianças difíceis e imprevisíveis na luta por justiça social, política e econômica" (BUTLER, 2018, p. 66). Acreditamos, em suma, que os teóricos-ativistas de Bishkek internalizaram com habilidade e criatividade essa noção a partir de sua proposta pós-soviética de um comunismo-queer, capaz de romper com as rígidas fronteiras da política identitária essencialista.

\section{CONSIDERAÇÕES FINAIS}

O desenrolar do presente trabalho nos indica, ao menos provisoriamente, a possibilidade de diálogo entre as discussões erigidas pela crítica de Butler e pela

33 "Like many words in English, 'queer' can be used as several parts of speech - as an adjective, a noun and a verb. As an adjective it means 'strange' or 'odd', referring to all things 'differing in some odd way from what is usual or normal' (Merriam-Webster Online Dictionary). 'Queer' in this sense designates a quality of departure from the perceived norm” (SUYARKULOVA, 2019, p. 47). 
teoria queer e alguns pontos do marxismo crítico contemporâneo, de modo a extrapolar os marcos simplistas da distinção entre marxismo e pós-estruturalismo, comumente construída a partir de noções estereotípicas de cada um dos lados dessa relação.

Cumpre reforçar, no entanto, que não estamos afirmando a plena coincidência dessas vertentes, como se, no fim, todos defendessem exatamente nas mesmas coisas ou que não haja erros, falhas e resquícios indesejados na obra marxiana ou em Butler. O central aqui não é o que Marx ou os marxistas disseram exatamente (a "verdade" transcendental acerca do realmente significariam seus textos), mas sim as possibilidades e provocações em suas obras que permitem repensar radicalmente a realidade a partir dos marcos de movimentos de grupos e pautas que questionam a normatividade vigente, entendidos aqui não na sua mesmidade, mas na sua existência como um inequivocamente outro que nos provoca a deixar de lado nossas certezas mais aferradas e formular uma ontologia crítica de nossa relacionalidade social e um questionamento das formas sociais que nos constituem de certa maneira e naturalizam certas formas de pensar e de agir. Particularmente, parece-nos que a experiência do comunismo-queer, nascida no seio do movimento LGBTQIA+ de semicolônias soviéticas da Ásia Central, é um instigante indicativo da possibilidade desse diálogo e da operação de deslocamentos de sentido que nos auxiliam a pensar justamente no significado mais dinâmico, contingente e singular de crítica.

\section{REFERÊNCIAS}

ALLEN, Amy. The end of progress: decolonizing the normative foundations of critical theory. Nova York: Columbia University Press, 2016.

ANDERSON, Kevin B. Marx at the Margins: on Nationalism, Ethnicity and NonWestern Societies. Chicago: The University of Chicago Press, 2010.

ARENDT, Hannah. Tradition and the Modern Age. Em: ARENDT, Hannah. Between Past and Future: Six Exercises in Political Thought. Nova York: The Viking Press, 1961, p. 17-40.

BROWN, Wendy. American nightmare: neoliberalism, neoconservatism and dedemocratization. Political Theory, [s. I.], v. 34, n. 6, p. 690-714, dez. 2006. 
BROWN, Wendy. Introduction. Em: ASAD, Talal; BROWN, Wendy; BUTLER, Judith; MAHMOOD, Saba. Is critique secular?: blasphemy, injury and free speech. Berkeley: The Townsend Center for the Humanities, University of California, 2009, p. 7-19.

BROWN, Wendy. Undoing the Demos: neoliberalism's stealth revolution. Nova York: Zone Books, 2015.

BROWN, Wendy Sacrificial Citizenship: neoliberalism, human capital and austerity politics. Constellations, [s. I.], v. 23, n. 1, p. 3-14, 2016.

BUTLER, Judith. Contingent foundations: feminism and the question of postmodernism. Em: BENHABIB, Seyla; BUTLER, Judith; FRASER, Nancy; CORNELL, Drucilla. Feminist contentions: a philosophical exchange. Nova York: Routledge, 1995a, p. 35-58.

BUTLER, Judith. For a careful reading. Em: BENHABIB, Seyla; BUTLER, Judith; FRASER, Nancy; CORNELL, Drucilla. Feminist contentions: a philosophical exchange. Nova York: Routledge, 1995b, p. 127-144.

BUTLER, Judith. The sensibility of critique: response to Assad and Mahmood. Em: ASAD, Talal; BROWN, Wendy; BUTLER, Judith; MAHMOOD, Saba. Is critique secular?: blasphemy, injury and free speech. Berkeley: The Townsend Center for the Humanities, University of California, 2009, p. 101-136.

BUTLER, Judith. O que é a crítica: um ensaio sobre a virtude de Foucault. Cadernos de Ética e Filosofia Política, São Paulo, v. 1, n. 22, p. 159-179, 2013.

BUTLER, Judith. Corpos em aliança e a política das ruas: notas para uma teoria performativa de assembleia. Rio de Janeiro: Civilização Brasileira, 2018.

BUTLER, Judith.; ATHANASIOU, Athena. Dispossession: the performative in the political. Cambridge: Polity Press, 2013.

COMUNA A. M. KOLLONTAI. Исторический материализм, советская власть и вопросы пола на современном этапе [Materialismo histórico, poder soviético e questões de gênero no estágio atual]. Em: MAMEDOV, Georgiy (ed.); SHATALOVA, Oksana (ed.). Бишкек утопический: сборник текстов [Bishkek utópica: coletânea de textos]. Bishkek: Friedrich Ebert Stiftung, 2015. p. 192-204.

DUSSEL, Enrique. Hacia un Marx desconocido: un comentario de los Manuscritos del 61-63. Cidade do México: Siglo XXI Editores, 1988. 
FONSECA, Angela Couto Machado. Crítica da subjetividade e a crise do humano: Butler, pós-estruturalismo e performatividade. Reflexiones Marginales, Cidade do México, n. 54, 2019. Disponível em: shorturl.at/cfqK5. Acesso em: 30 jul. 2020.

GOLDMAN, Wendy Z. Women, the State and Revolution: Soviet Family Policy and Social Life, 1917-1936. [s. I.]: Cambridge University Press, 1993.

HATHERLEY, Owen. 'Where our tomorrow is already yesterday': Bishkek. Em: HATHERLEY, Owen. The adventures of Owen Hatherley in the Post-Soviet Space. Londres: Repeater Books, 2018.

HEINRICH, Michael. An introduction to the three volumes of Karl Marx's Capital. Nova York: Monthly Review Press, 2012, p. 29-38.

HORKHEIMER, Max. Teoria tradicional e teoria crítica. Em: HORKHEIMER, Max; ADORNO, Theodor W.; BENJAMIN, Walter; HABERMAS, Jurgen. Textos Escolhidos. São Paulo: Abril Cultural, 1975.

HOY, David Couzens. Critical Resistance: From Poststructuralism to Post-Critique. Cambridge: The MIT Press, 2004.

KAGARLITSKY, Boris. Empire of the Periphery: Russia and the World System [Периферийная империя: циклы русской истории, Império periférico: ciclos da história russa]. Londres: Pluto Press, 2008.

LAVAL, Christian; DARDOT, Pierre. A nova razão do mundo: ensaios sobre a sociedade neoliberal. São Paulo: Boitempo, 2016.

LAVAL, Christian; DARDOT, Pierre. Comum: ensaio sobre a revolução no século XXI. São Paulo: Boitempo, 2017.

LOWY, Michael. A teoria da revolução no jovem Marx. 1. ed. ampl. e atual. São Paulo: Boitempo, 2012.

LUDWIG, Celso Luiz. Para uma filosofia jurídica da libertação: paradigmas da filosofia, filosofia da libertação e direito alternativo. Florianópolis: Conceito Editorial, 2006.

LYOTARD, Jean-François. The Postmodern Condition: A Report on Knowledge. Minneapolis: University of Minnesota, 1984.

MAMEDOV, Georgiy; SHATALOVA, Oksana. Квир-коммунизм это этика [О comunismo-queer é uma ética]. [s. I.]: Свободное марксистское издательство, 2016.

MAMEDOV, Georgiy; SHATALOVA, Oksana. Contra las respuestas sencillas. La teoría queer-comunista de Évald Iliénkov y Aleksander Suvórov. Disponível em: <shorturl.at/fhQ16>. Acesso em: 30 jul. 2020. 
MAMEDOV, Georgiy; SHATALOVA, Oksana. Коготок увяз - всей птичке пропасть. Квир-коммунистическая теория Эвальда Ильенкова и Александра Суворова [Quando as garras aparecem, os passarinhos fogem. A teoria queer-comunista de Eval'd Il'enkov e de Aleksandr Suvorov]. Гендерные исследования [Investigações de gênero], [s. I.], n. 22, p. 112-139, 2017.

MARINHO, Cristiane. Novas relações de poder e novas resistências: corpos em aliança como resistência à precariedade neoliberal. Em: MARTINS, Ana Claudia Aymoré (org.); VERAS, Elias Ferreira (org.). Corpos em aliança: diálogos interdisciplinares sobre gênero, raça e sexualidade. Curitiba: Appris, 2020, p. 117-138.

MARX, Karl. Ad Feuerbach (1845). Em: MARX, Karl; ENGELS, Friedrich. A ideologia alemã. São Paulo: Boitempo, 2007, p. 533-535.

MARX, Karl. Prefácio. Em: MARX, Karl. Contribuição à crítica da economia política. 2 ed. São Paulo: Expressão Popular, 2008, p. 45-50.

MARX, Karl. Carta à redação da Otechestvenye Zapiski, 1877. Em: MARX, Karl; ENGELS, Friedrich; LOWY, Michael (org.). Lutas de Classes na Rússia. São Paulo: Boitempo, 2013a.

MARX, Karl. O Capital: Crítica da economia política. São Paulo: Boitempo, 2013b.

MIELI, Mario. Towards a gay communism: elements of a homosexual critique. Londres: Pluto Press, 2018.

MUSTO, Marcello. O velho Marx: uma biografia de seus últimos anos (1881-1883). São Paulo: Boitempo, 2018.

MUSTO, Marcello (ed.). Marx's Capital after 150 Years: Critique and Alternative to Capitalism. Nova York: Routledge, 2019.

QUIJANO, Anibal. Colonialidade do poder, eurocentrismo e América Latina. Em: LANDER, Edgardo (org.). A colonialidade do saber: eurocentrismo e ciências sociais. Perspectivas latinoamericanas. Buenos Aires: CLACSO, 2005, p. 227-278.

PETCHESKY, Rosalind P. Owning and disowning the body: a reflection. Em: BAKSH, Rawwida (ed.); HARCOURT, Wendy (ed.). The Oxford Handbook of Transnational Feminist Movements. Nova York: Oxford University Press, 2015, p. 252-270.

RODRIGUES, Carla. Para além do gênero: anotações sobre a recepção da obra de Butler no Brasil. Em Construção: arquivos de epistemologia histórica e estudos da ciência, Rio de Janeiro, n. 5, p. 59-72, 2019. 
SEGATO, Rita Laura. Gênero e Colonialidade: em busca de chaves de leitura e de um vocabulário estratégico descolonial. Tradução de Rose Barboza. Revista ECadernos, Coimbra, n. 18, 2012. Disponível em: <eces.revues.org/1533>. Acesso em: 07 ago. 2020.

ShTAB. SHKOLA TEORII I AKTIVIZMA. Манифест Квир-Комунизма [Manifesto do Comunismo-Queer]. Юдоль, [s. І.], п. 1, р. 22, mar. 2015. Disponível em: <shorturl.at/amBDX>. Acesso em: 06 de ago. de 2020.

SOLOMKO, Zarianna Vladimirovna. Права человека и правовое государство с позиции марксизма: общее и особенное [Direitos humanos e estado de direito desde a posição do marxismo: o geral e o particular]. Em: SINYUKOV, Vladimir Nikolaevitch (ed.). Обеспечение прав и свобод человека в современном мире: материалы конференции: в 4 ч. Часть 1 [Garantia de direitos e liberdades do ser humano no mundo moderno: materiais da conferência: em quatro partes. Parte 1]. Moscou: Проспект, 2017, p. 36-40.

SOUSA SANTOS, Boaventura de. Tudo que é sólido se desfaz no ar: o marxismo também? Em: SOUSA SANTOS, Boaventura de. Pela mão de Alice: o social e o político na pós-modernidade. 7. ed. Porto: Edições Afrontamento, 1999, p. 25-48.

SOUSA SANTOS, Boaventura de. A crítica da razão indolente: contra o desperdício da experiência. 4. ed. São Paulo: Cortez, 2002.

SUYARKULOVA, Mohira. Translating 'Queer' into (Kyrgyzstani) Russian. Em: COTTET, Caroline (ed.); PICQ, Manuela Lavinas (ed.). Sexuality and Translation in World Politics. Bristol: E-International Relations Publishing, 2019, p. 42-56. 